\title{
STRUCTURAL MECHANISM OF THE HIGH-DAMPING STATE FORMATION IN THE Fe-Mn-Si SHAPE MEMORY ALLOYS
}

\author{
V.A. Udovenko, N.A. Polyakova and T.A. Turmambekov \\ Central Research Institute of Iron and Steel Industry (State Scientific Centre) \\ Moscow 107005, Russia
}

The structural mechanism of the high-damping state formation in the $\mathrm{Fe}-\mathrm{Mn}-\mathrm{Si}$ alloys has been investigated using transition electron microscopy and logarithmic decrement measurements. The high level of the elastic energy dissipation was found to be connected with a reversible movement of the Shockley dislocations under the sign changing stress action. The Shockley dislocations density and mobility are controlled by the alloys compositions and prior deformation value. The increase in the dislocations density with the help of the special cycling treatments can improve the alloys damping capacity.

PACS numbers: $61.16 .-\mathrm{d}, 75.50 . \mathrm{Bb}, 75.60 . \mathrm{Ej}, 75.80 .+\mathrm{q}$

The alloys of the $\mathrm{Fe}-\mathrm{Mn}-\mathrm{Si}$ system containing 26-32 at\% $\mathrm{Mn}$ and 3-6 at\% Si with $\gamma \leftrightarrow \varepsilon$ martensitic transformation are known as promising shape memory alloys for large scale devises and equipment. Lately it has been established that after previous deformation these alloys exhibit another special feature - high-damping capacity $[1,2]$. The high-damping state is obviously connected with the particularities of the deformed alloys structure. The aims of the present work are to clear up the structural mechanism of the high-damping state formation in these alloys and to determine both the optimal high-damping structure and the preparation technology.

The alloys, containing 26-36 at\% Mn and 3-6.5 at\% Si, have been studied. The samples for investigation were cut from quenched and cold rolled rods (with different degrees of deformation). The measurements of the damping capacity (logarithmic decrement values) were carried out using the method of inverted banding pendulum at room temperature. The structural investigations have been performed by transmission electron microscopy.

The alloys in the quenched state do not exhibit very high-damping capacity - the value of the logarithmic decrement does not exceed $2-4 \%$. The deformation leads to the increase in the damping capacity, and the $\delta$ dependence on the 
deformation value has the shape of the smooth curve with an obvious maximum, corresponding to the intermediate deformation values, $5-10 \%$, depending on the alloys composition. The study of the set of the alloys shows the existence of the strong concentration dependence of the damping capacity (Fig. 1). Its character was rather unexpected. There is an obvious minimum in the range of the compositions, which are the most favorable for perfect shape memory effect.
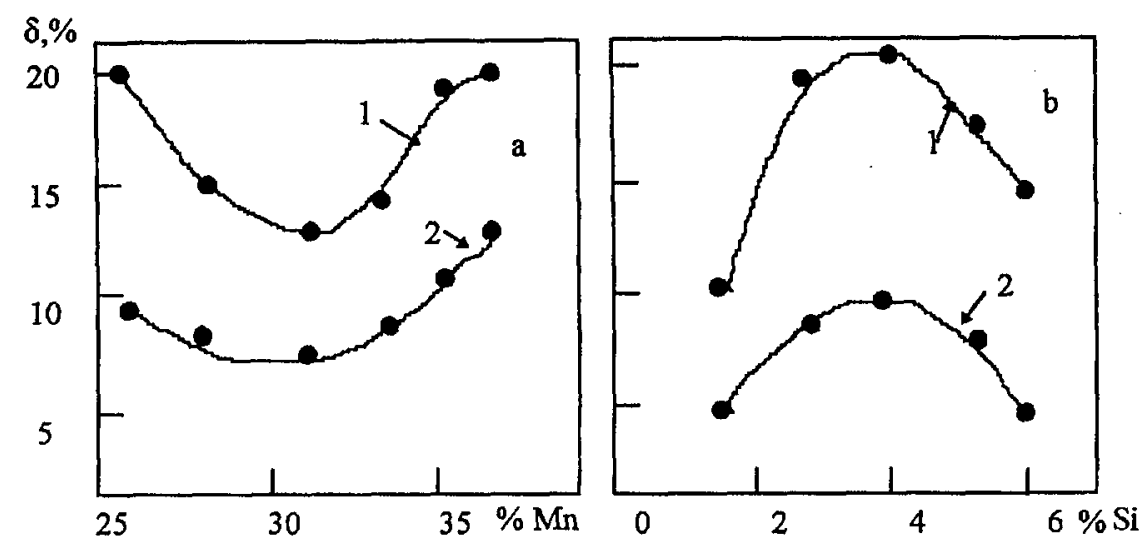

Fig. 1. Mn (a) and Si (b) content effect on the logarithmic decrement value of the $\mathrm{Fe}-\mathrm{Mn}-\mathrm{Si}$ alloy. The amplitude of the deformation $\varepsilon=2.5 \times 10^{-3}(1)$ and $1.5 \times 10^{-3}(2)$.

The amplitude dependence of the damping capacity has a quite different behavior than the one usually observed in the alloys with thermoelastic martensitic transformation. In the $\mathrm{Fe}-\mathrm{Mn}-\mathrm{Si}$ alloys there is a continuous growth of the logarithmic decrement $\delta$ in accordance to the near parabolic law up to the yield stress of the material as amplitude of the deformation increases (Fig. 2). Such a character of the $\delta$ amplitude dependence is a particular feature of alloys with the increased level of the energy dissipation caused by dislocation movement.

Taking into account that $\gamma-\varepsilon$ martensitic transformation in the $\mathrm{Fe}-\mathrm{Mn}-\mathrm{Si}$ alloys of the investigated compositions occurs due to the motion of Shockley dislocations [3], it is reasonable to suppose that namely the latter ones are the easy. movable structural elements, which determine the high level of the damping capacity of the $\mathrm{Fe}-\mathrm{Mn}-\mathrm{Si}$ alloys.

The results of the electron microscopy investigation of the deformed alloys show that two kinds of the defects caused by the Shockley dislocations can be introduced in the alloy by deformation: single layer unbalanced stacking faults (SFs) and multilayer SFs that are the nuclei of the $\varepsilon$-martensite. Depending on the alloys composition (Mn and $\mathrm{Si}$ contents) the first or the second kinds of the defects predominate in the deformed alloy. The multilayer stacking faults predominate in the alloys containing $29-30 \% \mathrm{Mn}$ and $5.5-6 \% \mathrm{Si}$ (shape memory alloys). The deviation from the above composition leads to the increase in the relative contribution to the deformation, connected with the single layer SF formation (Fig. 3). It is necessary to note that the highest value of the single layer SF density is reached 


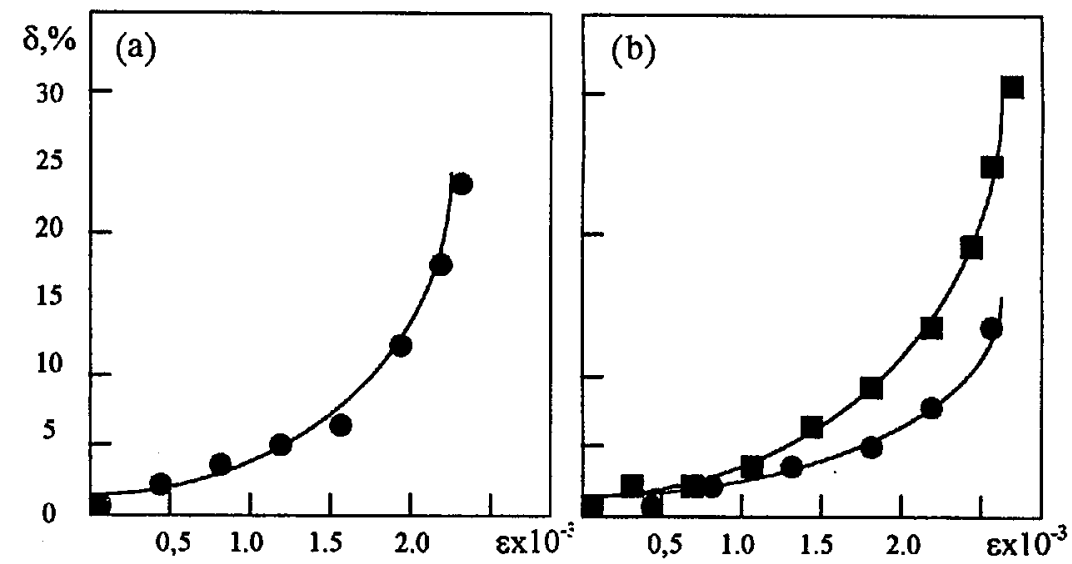

Fig. 2. Amplitude dependence of the $\delta$ values of the Fe-27Mn-5.5Si (a) and Fe-30Mn-6Si (b) alloys, - - cold rolled sample, $\mathbf{a}$ - cycling treated sample.
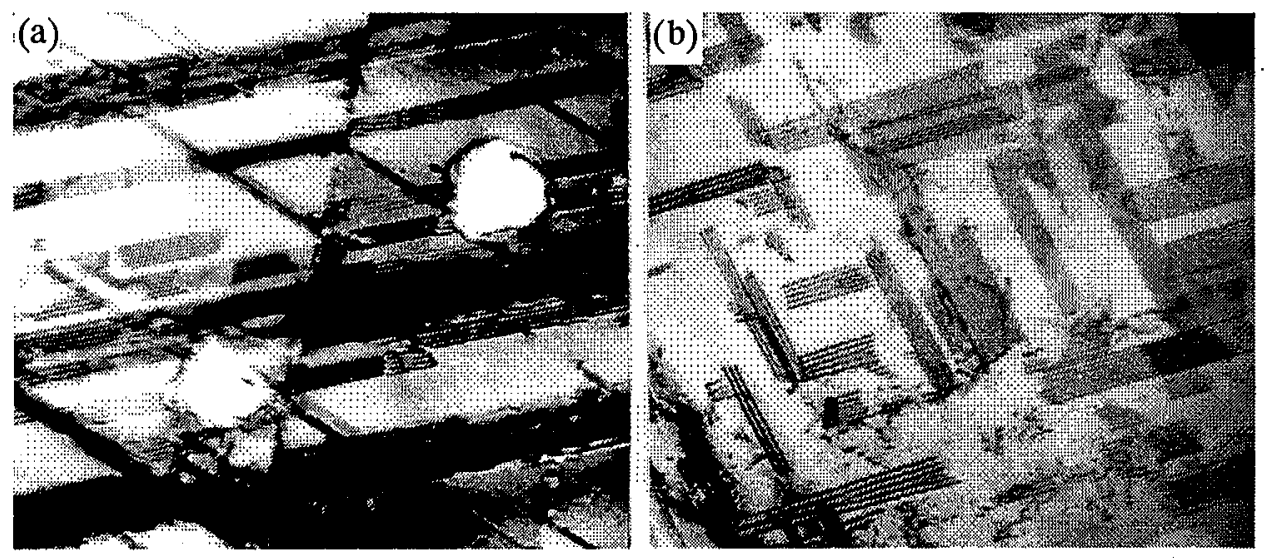

Fig. 3. Electron microscopy images of the deformed structure of the Fe-30Mn-6Si (a) and $\mathrm{Fe}-27 \mathrm{Mn}-5.5 \mathrm{Si}(\mathrm{b})$ alloys.

upon the intermediate deformation degrees (not exceeding 10-12\%). Then their local density does not increase and relative density even decreases the expense of the $\varepsilon$-martensite fraction.

The analysis of the data on the structure and damping properties of the $\mathrm{Fe}-\mathrm{Mn}-\mathrm{Si}$ alloys shows that the high fraction of the $\varepsilon$-martensite is not the necessary condition for the highest level of the damping properties formation. The optimum from this point of view is the structure of two-phase mixture of $\varepsilon$-martensite and $\gamma$-phase, containing a high density of the Shockley dislocations.

If our conclusions on the mechanisms of the high-damping state formation in the $\mathrm{Fe}-\mathrm{Mn}-\mathrm{Si}$ alloys are valid, it is possible to develop the special treatments which can improve the damping capacity of the $\mathrm{Fe}-\mathrm{Mn}-\mathrm{Si}$ alloys with the perfect shape memory effect. Such alloys are very attractive for the practical application 
because they possess the combination of several special properties (shape memory, high damping, pseudoelasticity) and exhibit the best mechanical properties among the $\mathrm{Fe}-\mathrm{Mn}-\mathrm{Si}$ alloys.

The idea of the special treatment is based on using the combination of the deformation and heat treatments which cause the increase in the Shockley dislocations density in the alloys. The sample of $\mathrm{Fe}-30 \mathrm{Mn}-6 \mathrm{Si}$ alloy was quenched from $800^{\circ} \mathrm{C}$ then deformed up to $5 \%$ (optimal value of the deformation). Then, this sample was heated at $500^{\circ} \mathrm{C}(T>$ martensitic transformation temperature). The electron microscopy study shows that the stress induced martensite disappeared, but the density of dislocations remains higher than that in the quenched sample. Then the sample was deformed again up to $5 \%$. As can be seen from Fig. $2 \mathrm{~b}$ the values of logarithmic decrement reach $30 \%$ which is a very high level for the $\mathrm{Fe}-\mathrm{Mn}-\mathrm{Si}$ alloy.

It should be noted that the favorable effect of deformation on the damping properties of the alloy is a particular feature of $\mathrm{Fe}-\mathrm{Mn}-\mathrm{Si}$ alloys; as a rule, deformation of the martensitic alloys leads to degradation of damping properties due to the pinning of movable boundaries on defects, introduced by deformation.

Deformed $\mathrm{Fe}-\mathrm{Mn}-\mathrm{Si}$ alloys have a superior level of the damping and the mechanical properties, combining high strength and high plasticity $\left(\sigma_{02}=\right.$ $700-900 \mathrm{MPa}, \sigma_{B}=800-1000 \mathrm{MPa}, \Delta=25-30 \%$ ). Additional advantages of the $\mathrm{Fe}-\mathrm{Mn}-\mathrm{Si}$ alloys are their low cost and easy manufacturing method: there are no problems with their melting or workability. In this connection they can be recommended for the use in the large size devices and constructions for controlling the vibrations and deformations of large amplitudes.

\section{References}

[1] A. Sato, K. Ozaki, Y. Watanabe, T. Mori, Mater. Sci. Eng. A 101, 25 (1988).

[2] K.K. Jee, W.Y. Jang, S.H. Baik, M.C. Shin, C.S. Choi, J. Phys. III Colloq. C 8 5, 385 (1995).

[3] H. Otsuka, H. Yamada, T. Maruyama, H. Tanahachi, S. Matsuda, M. Murakami, Iron Steel Institute Japan (ISIJ) Internat. 30, 674 (1990). 